\title{
Assessing agro-morphological diversity of chickpea accessions in western Algeria
}

\author{
Bouri A ${ }^{1,2^{*}}$, Mediouni M.R. ${ }^{2}$, Kaouadji $Z^{2}$, Meghili I ${ }^{2}$, Gaouar S.B.S ${ }^{2}$ \\ 1 Higher Agronomic school-Mostaganem- Algeria \\ 2 Laboratory of physiology, physiopathology and biochemistry of nutrition "PPABIONUT". \\ Department of biological Sciences. Abou BekrBelkaid University Tlemcen 13000-Algeria.
}

\begin{abstract}
*Corresponding Author: BOURI A. Higher Agronomic school -Mostaganem- Algeria; Email:bouri.amina@ymail.com
\end{abstract}

\begin{abstract}
The chickpea is a very important food species in Algeria whose cultivated type is Kabuli and it is the one of the largest seed legumes. Ten chickpea genotypes were characterized for different agro-morphological traits in order to estimate the genetic diversity. For this purpose, an experimental culture test (completely randomized block system) was conducted at the pilot farm of El Hamaddouche in Tlemcen. Analysis of variance showed a high level of significance for many traits. The Shannon and Weaver index $\mathrm{H}^{\prime}$ (mean) of this collection $(0.29)$ reflects a weak morphological diversity. The principal component analysis (PCA) was performed for all traits and explained $60.43 \%$ of the total variability. The genotypes were grouped into five clusters by reference to the chosen axes. Genotypes forming the same group are closely related to each other according to their common agro-morphological traits, the same pattern was observed for the Hierarchical Ascendent Classification (HAC). Cluster analysis and correspondence analysis summarizes that there is a close resemblance between genotypes from different regions, implying that there are no relationships between geographic origins and genetic diversity. Keywords: Chickpea, agro-morphological trait, genetic diversity, Shannon and Weaver index H', PCA, HAC
\end{abstract}

\section{Introduction}

Chickpea (Cicerarietinum L.) is a self-pollinated diploid $(2 \mathrm{n}=2 \mathrm{x}=16)$, annual leguminous plant in the family Fabacea with a genome size of 738.09 Mbp (Varshney et al., 2013).

The Kabuli type chickpea is a very important food crop in Algeria .It ranks second after the bean and is mostly cultivated in the western part of the country (MADR, 2018).

The cultivation of chickpeas constitutes an important component in production systems in Algeria, in semi-arid regions of the Mediterranean basin where water resources are in constantly regression, farmers are realizing the significant role which this species plays in organic soil fertilization, This species is cultivated on an annual surface (average) of 33 thousand ha or $36.78 \%$ of the surface of the legumes seeds. Production is characterized by interannual fluctuations; 351 thousand quintals on average with an average yield of $10 \mathrm{q} / \mathrm{ha}$, Chickpea production is very low and the food selfsufficiency rate only represents $27.7 \%$ (MADR, 2014).

During the colonial period, several works of inventories, characterization and improvement were undertaken on the local cultivars and showed strains from the local originate more interesting in terms of earliness and productivity than the varieties of introduced especially from European countries. Nevertheless, over time no collections of our chickpea accessions could be preserved and presented. 
Therefore, the collection and adequate evaluation of local genetic resources becomes essential in order to select and develop varieties with good yield, adaptable to climatic variations and resistant to diseases and insect pests. In this work, 10 chickpea cultivars at Northwestern Algeria region will be assessed for their agronomic potential and genetic variability via Morphometric marker

\section{Material and methods}

\section{Plant material}

Ten chickpea genotypes (Cicerarietinum L.); including three landraces collected from different geographical locations of north west of Algeria, one landrace from Italia and 6 breeding lines introduced from ICARDA (Syria) and Turkey in Algeria and one accession from Spain; were considered for the study of genetic diversity (Table 1).

Table 1. List of chickpea genotypes used for morphological characterization

\begin{tabular}{lllll}
\hline Sl. No. & Accessions & Origin & Biological status & Type \\
\hline $\mathbf{1}$ & GARB ANSA 9 & Algeria & Landrace & Kabuli \\
$\mathbf{2}$ & BLED 6 & Algeria & Landrace & Kabuli \\
$\mathbf{3}$ & F10 38 & Algeria & Landrace & Kabuli \\
$\mathbf{4}$ & FLIP 8293 & Syria (ICARDA) & breeding line & Kabuli \\
$\mathbf{5}$ & FLIP 8492 C & Syria (ICARDA) & breeding line & Kabuli \\
$\mathbf{6}$ & FLIP 9213 C & Syria (ICARDA) & breeding line & Kabuli \\
$\mathbf{7}$ & FLIP 9393 C & Syria (ICARDA) & breeding line & Kabuli \\
$\mathbf{8}$ & ILC 482 & Turkey & breeding line & Gulabi \\
$\mathbf{9}$ & ESP 1 & Spain & breeding line & Kabuli \\
$\mathbf{1 0}$ & CECE NERO & Italia & Landrace & Desi \\
\hline
\end{tabular}

\section{Experimental design and trial management}

The seeds of the chickpea genotypes were sown in the field of pilot farm. (EURL Hamadouche at the level of the safsafdaïra of Chetouanewilaya of Tlemcen) in North West Algeria having altitude of 583 $\mathrm{m}$, longitude $1^{\circ} 17^{\prime} 51.26$ "W, latitude $34^{\circ} 55^{\prime} 13.08 " \mathrm{~N}$ ) whose bioclimatic is semi-arid.

The soil has a balanced texture; the coarse fraction is medium with a high organic matter content, at neutral $\mathrm{pH}$.

The experiment followed a randomized block design with five repetitions (50 blocks). A unit plot size was $2.0 \mathrm{~m} \times 2.0 \mathrm{~m}$ (Fig.1). The seeds were sown on 27 December 2018 at $30 \mathrm{~cm}$ distances within rows of $2.0 \mathrm{~m}$ apart.

Recommended cultural and intercultural operations like weeding, irrigation, insect-pest control measures were also followed.

The data of morphological, and agronomical traits were collected during the growth period of the crop, depending on the descriptors for chickpea chosen according to international standards, particularly those of the International Plant Genetic Resources Institute (IPGRI 1985), currently named Biodiversity International and Protection Union of New Varieties of Plants (UPOV. 2005).

Data were recorded on plant height (PH), number of branch per plant (NBR.PT), number of leaflets per leaf (Nlf.LF), leaflet width (LW), leaflet length (LL), number of pods per branch (NP.BR), number of pods per plant (NP.PT), number of single seed pods per plant (NP1), number of pods with two seeds per plant (NP2), pod width (PW), pod length (PL), number of seeds per plant (NS.PT), seed width (SW) and seed length (SL) were recorded from randomly selected 30 competitive plants from each plot. 
Bouri et al. 2021. Gen. Biodiv. J, Special issue (Characterization and valorisation of Plants),49-58

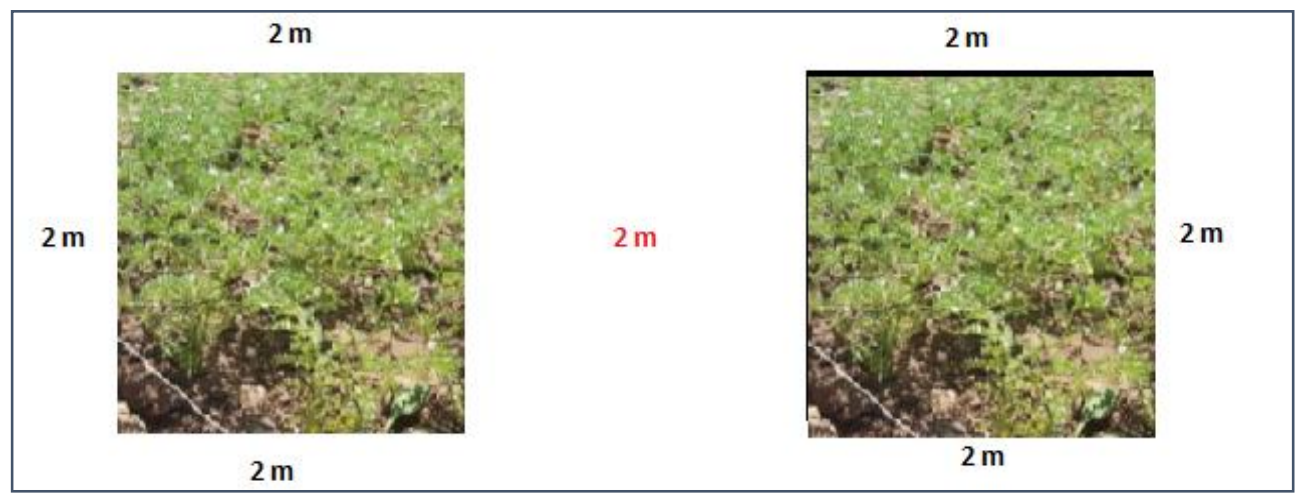

Figure 1. Experimental device (Bouri A. chickpea in flowering (April 2019)

\section{Data Collection}

The plant material consists of whole chickpea plants with pods and seeds. Three hundred (300) samples were used and served as a tool for this study.

\section{Morphological data}

Accessions were evaluated using 14 characters having variations of quantitative type. These characters are:

1. plant height $\mathrm{PH}(\mathrm{cm})$

2. number of branch per plant NBR.PT

3. number of leaflets per leaf NIf.LF

4. leaflet width LW

5. leaflet length LL

6. number of pods per branch NP.BR

7. number of pods per plant NP.PT

8. number of single seedpods per plant NP1

9. number of pods with two seeds per plant NP2

10.pod width PW

11.pod length PL

12.number of seeds per plant NS.PT

13.seed width SW

14.seed length SL

\section{Statististical Analysis}

The data were analysed following randomized complete block design (RCBD).Shannon and Weaver Index and principal components (PCA) analyses were also made using software R (version R2.15.3).

Finally, the hierarchical classification (cluster) has been established using the median method.

Significance analysis of these parameters was performed by $\chi 2$-test $(\mathrm{P}<0.05)$, and Tukey Test. $(\mathrm{P}<$ $0.05)$ with R statistical software.

\section{Shannon and Weaver Index}

Before proceeding to this test, the quantitative traits were transformed into classes. This transformation was done using (summary) of the R software, which divided these data into the desired number of classes (in our case four classes). In parallel, we determined the limit of each class. The frequencies of these different phenotypic classes were calculated for each line.

The index of Shannon-Weaver (Shannon and Weaver, 1948) which was described by Jain et al (1975) was calculated for each line in order to estimate the genetic diversity. Genetic diversity in this case 
Bouri et al. 2021. Gen. Biodiv. J, Special issue (Characterization and valorisation of Plants),49-58

because all the accession are grown in the same environment.

The Shannon-Weaver index formula is:

$$
\begin{aligned}
& \mathbf{H}=-\sum_{\mathrm{i}=1}^{\mathrm{n}} \mathbf{P i} \mathbf{L n} \mathbf{P i} \\
& \mathbf{H}=\text { Shannon and Weaver diversity index } \\
& \mathbf{P i}=\text { Frequency of each phenotypic class } \mathrm{i} \text { of a given character } \\
& \mathbf{n}=\text { Number of phenotypic classes of each character. }
\end{aligned}
$$

The index $(\mathrm{H})$ is converted to the relative phenotypic diversity index $\left(\mathrm{H}^{\prime}\right)$ by dividing it by its maximum value: $\mathrm{H} \max (\mathrm{Ln}(\mathrm{n}))$ to obtain values from 0 to 1 .

$$
H^{\prime}=-\sum_{i=1}^{n} \operatorname{Pi} \operatorname{Ln} P i / \operatorname{Ln}(n)
$$

The relative diversity index $\left(\mathrm{H}^{\prime}\right)$ reaches its minimum value, which is zero for monomorphic characters. In addition, the value of this index increases with the degree of polymorphism and reaches a maximum value (1) when all the phenotypic classes are present at equal frequencies.

Principal Components Analysis (PCA):

Principal components analysis was carried out on the correlation matrix. It calculated the mean data of accessions using the FactoMineR software (version R-2.15.3).

\section{Hierarchical Ascendent Classification (HAC):}

Hierarchical Ascendent Classification or cluster analysis was used to calculate the mean data of accessions using the FactoMineR software (version R-2.15.3) to better classify the 10 accessions of chickpea.

Significance analysis of these parameters was performed by $\chi 2$-test $(\mathrm{P}<0.05)$, and Tukey test $(\mathrm{P}<$ $0.05)$ with $\mathrm{R}$ statistical software.

\section{Results and discussion}

\section{Variance analysis}

The genotypes showed highly significant differences for all the studied traits except SW and SL (Table 2).

Plant height $(\mathrm{PH})$ of the genotypes ranged from $10.5 \mathrm{~cm}$ for FLIP $8492 \mathrm{C}$ to $79 \mathrm{~cm}$ for FLIP $9393 \mathrm{C}$. Number of branch per plant (NBR.PT) ranged from 0.6 for FLIP 8492 C to 25 for ESP 1, the number of leaflets per leaf (NLf.LF) ranges from 11 for FLIP 8293 to 26 for ESP1, leaflet width (LW) ranged from 4.31 for FLIP $9213 \mathrm{C}$ to 19.89 for FLIP 8293, leaflet length (LL) ranged from 2.01 for FLIP $9213 \mathrm{C}$ to 13.85 for BLED 6, number of pods per branch (NP.BR) ranged from zero for FLIP 8293 to 71 for FLIP 9213 C, number of pods per plant (NP.PT) ranged from 63 for ILC482 to 2310 for FLIP 82 93, number of single seed pods per plant (NP1) ranged from 52 for BLED 6 to 2299 for FLIP 8293, number of pods with two seeds per plant (NP2) ranged from one for CECE NERO to 271 for FLIP 8492 C, pod width (PW) ranged from 7.92 for CECE NERO to 27.97 for FLIP 9213 C, pod length (PL) ranged from 8.17 for FLIP $9213 \mathrm{C}$ to 39.46 for ESP1and finally number of seeds per plant (NS.PT) ranged from 66 for ILC 482 to 2321 for FLIP 8293 (Table 2).

A similar result was found by Bayahi and Rezgui (2015) in which the genetic material was composed of sixteen chickpea lines cultivated in the experimental area of the INRAT (Tunisian Agricultural Research National Institute) regarding the characters: PH; NGTP, NP1, NP2, Ng.PT, except for the Nlf.LF trait, which was found to be insignificant $(\mathrm{p}>0.01)$ and therefore according to their study this trait is dependent on the environment and make an important role in adaptation. 
In Bouri and Gaouar (2018) and in Bouri et al, (2019) the same result was found for the characters HP, NP.PT, NS.PT and the calibre of seed (SW x SL) and according to their statistical study (effect of the interaction between genotype environment) the response of these characters depends on the interaction between genotype and environment.

InVural and Karasu (2007) the total number of seed per plant NS.PT was the highest for the accession ILC 482 contrary to our result that has showed that this same accession gives the lowest seed number per plant.

\section{Relative diversity index ( $\left.H^{\prime}\right)$ of different characters}

The relative diversity index ( $\mathrm{H}^{\prime}$ mean) of all accessions is about 0.29 (Table 3).This index ranged from 0.2 to 0.425 , respectively, for the genotypes BLED 6 and ESP (1).

Over all, all characters revealed diversity ranging from 0.23 for the number of leaflets per leaf (NLf.LF) to 0.415 for leaflet width (LW) (Table3).

As follows, the highest diversity index (H'moyen), $\left(\mathrm{H}^{\prime}=0.59\right)$ was for leaft width (LW) of the CECENERO accession. The highest diversity index $\left(\mathrm{H}^{\prime} \geq 0,40\right)$ were obtained from two accessions (ESP 1 and FLIP 8492C); intermediate value $(0,30 \leq \mathrm{H}<0.40)$ was found from three accessions: FLIP 8293, FLIP 9393C and GARBANSA (9), while the low value $(0,10 \leq \mathrm{H}<0.30)$ were obtained from five accessions (F1038, ILC 842, CECE NERO, FLIP 9213C, BLED 6).

The Shannon and Weaver index H' (mean) of this collection (0.29) reflects a weak morphological diversity which was comparatively low than the value obtained by Hari $(2002)\left(H^{\prime}=0.507\right)$.

The high value of the diversity index in the collection in some characters was mainly due to the presence of polymorphic traits $\left(\mathrm{H}^{\prime}>0.50\right)$, in particular, the width of the leaf $(\mathrm{LW})\left(\mathrm{H}^{\prime}=0.59\right)$ found in the CECENERO accession

Concerning the plant height, the Shannon and Weaver Index (H') was only 0.38 ) which was relatively low than $\left(H^{\prime}=0.556\right)$ the one reported by Hari et al (2002), the same case is for the number of pods per plant NP.PT $\left(H^{\prime}=0.28\right)$ comparing to $\left(H^{\prime}=0.528\right)$ also in Hari et al $(2002)$.

While, for the number of seeds per plant NS. PT our result was close to the one obtained by Hari et $a l$, (2002) $\left(\mathrm{H}^{\prime}=0.293\right) V s\left(\mathrm{H}^{\prime}=0,352\right)$.

PCA of chickpea accessions of different characters for all individuals

In our analysis of 14 characters, the first principal component explains (CP1) $39.91 \%$ of the variability, the second (CP2) $20.52 \%$ of the variability and therefore a cumulative variability is $60.43 \%$. Therefore, the PCA of chickpea accessions reflects a high level of statistical significance (Fig 2).

The coefficients of the vectors of the quantitative descriptors studied and the two principal components show that a high structuring of the first component CP1 the following characters define (39.91\%) positively: PH, LW, LL, Nlf.LF, NBR.PT, NS.PT, NG.PT, NP.PT, NP1 and negatively with a single character NP.BR.

The second component CP2 (20.52\%) is defined positively by NP2 and PL and negatively by SL, SW, PW.

According to the result of PCA, we can deduce that the number of pods per branch NP.BR correlated negatively with plant height $\mathrm{PH}$, leaf weight $\mathrm{LW}$, leaf length LL, number of leaflet per leaf Nlf.LF, number of branch per plant NBR.PT , number of pods per plant NP.PT ,number of seeds per plant NS.PT and the of number of single seed pods per plant NP1.

The similar case have been found inKhamassi et al (2014), and in Kumar et al (2019) concerning the correlation between PH and NP.PT and in Jain et al (2021) concerning the PH, NP.PT and NS.PT.

There is a strongly positive correlation between the number of pods per plant NP.PT, the number of seeds per plant NS.PT and the number of single seedpods per plant NP1 while there is a negative correlation with the trait of the number of pods with two seeds NP2 with all of those three traits. This 
Bouri et al. 2021. Gen. Biodiv. J, Special issue (Characterization and valorisation of Plants),49-58

case was previously determined by a correlation test in Bouri and Gaouar (2018) and in Jain et al (2021).

The number of single seedpods per plant NP1 appears to increase with increasing number of total pods per plant NP.PT. According to Saxena and Singh (1987), in chickpeas the number of pods per plant varies from 30 to 150 , this number depends on environmental conditions; cultivars that produce the most pods also form the most single-seed pods and vice versa. So there is a compensating effect in this species, genotypes which produce a lot of pods give fewer pods to more than one seed and the opposite is true ; the same observation was given by Abdelguerfi et al (2001).

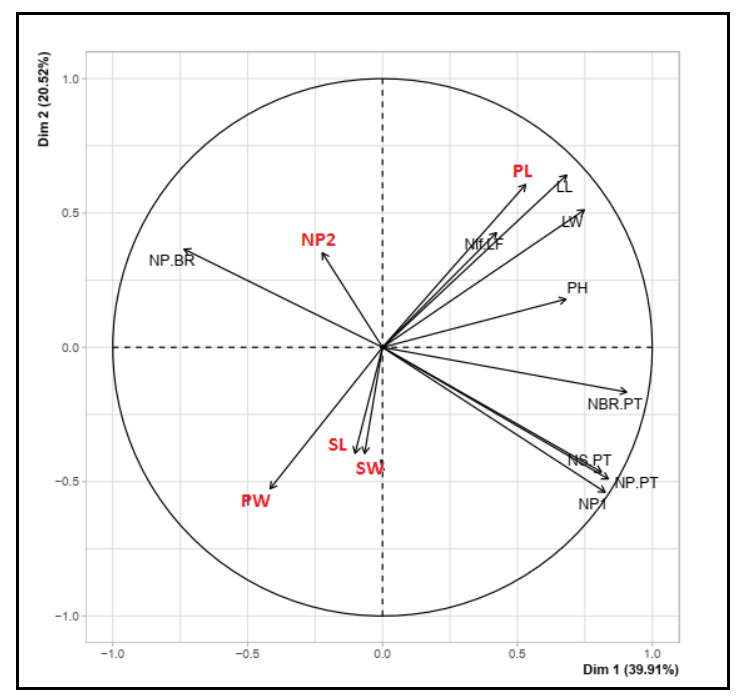

Figure 2. PCA of chickpea accessions according to the average of different characters for all individuals (explaining $60.43 \%$ of the total variability)

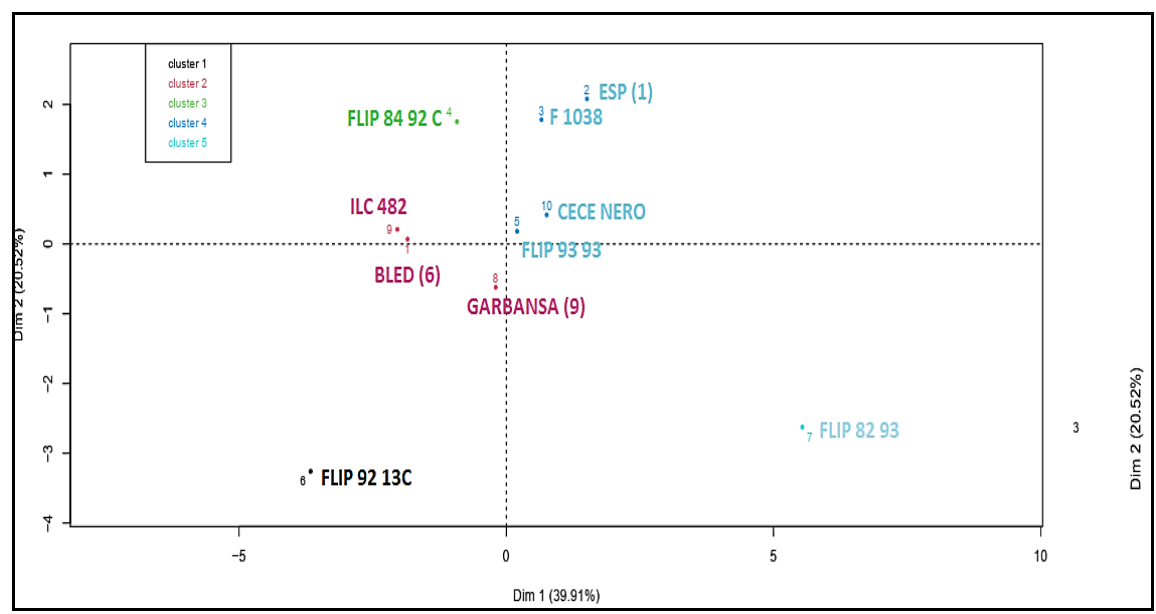

Figure 3. Projection of 10 chickpea accessions on the first two main axes of the PCA based on 14 quantitative descriptors 
Table 2.Averages and SD traits of chickpea accession

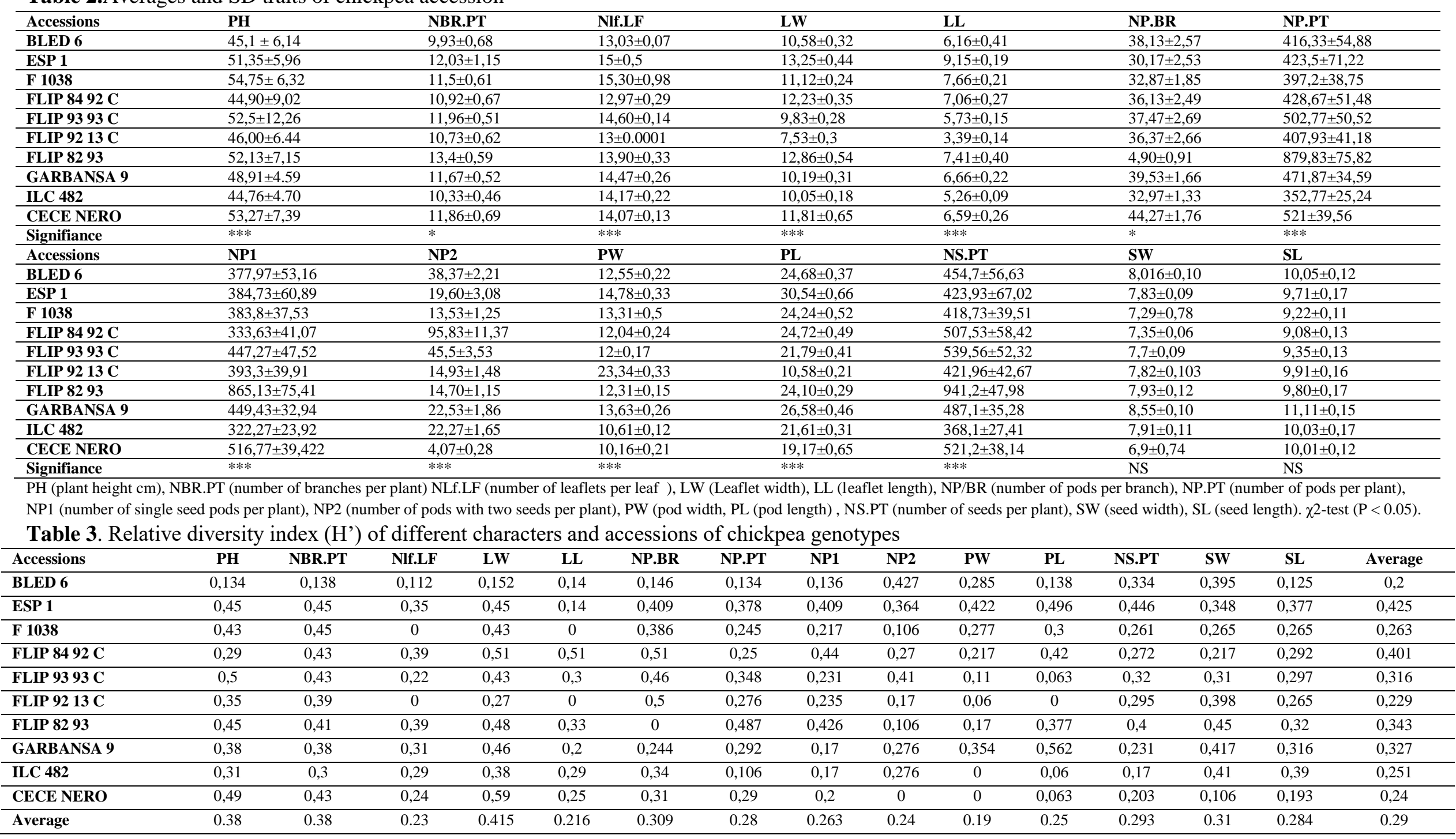


PCA (projection of genotypes)

The principal coordinate analysis PCA have separated genotypes in fives clusters. The first one includes FLIP 9213C, the second one contains ILC 482, BLED 6 and GARBANSA 9.the third contains FLIP 84 92C while the fourth includes ESP 1, F1038, CECE NERO, and FLIP 9393C. Finally the last one that contains FLIP 8293 (Fig 3).

There is a certain difference in the assembly of genotypes, for example, we find two local varieties grouped with two other breeding line (F1038, CECE NERO, ESP 1 and FLIP 9393C) in the cluster (4), and in the cluster (2) there are two Algerian landraces with a breeding line variety (BLED 6 , GARBANSA 9 and ILC 482).

According to this study, the grouping of these accessions is based on the genetic similarity that exists between certain genotypes.

\section{Hierarchical Ascendant Classification (HAC)}

The similar pattern was observed for the UPGMA dendrogram, five groups was designed based on the morphological parameters studied the first one includes FLIP 9213C, the second one contains ILC 482, BLED 6 and GARBANSA 9 the third contains FLIP 84 92C while the fourth includes ESP 1, F1038, CECE NERO, and FLIP 9393 C. Finally the last one that contains FLIP 8293 (Fig 4).

The same ten genotypes of chickpea were analysed using 20 SSR markers in order to describe the genetic diversity (Bouri et al, 2020), but the results of PCA and of the HAC are completely different from that obtained in this study through the morphological markers.

This may be due to the difference in the study approach and in relation to the influence of the environment conditions on our genotypes during their cultivation in fields and subsequently a variation in phenotypic expression.

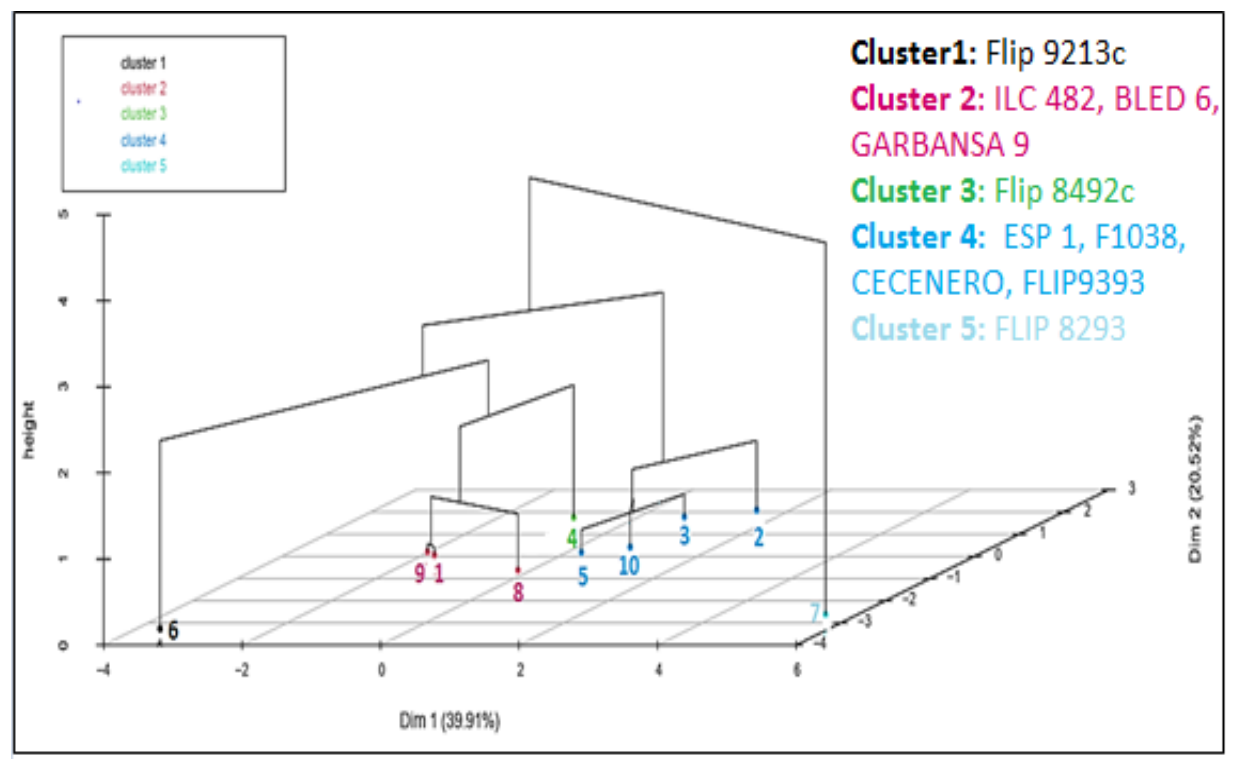

Figure 4. Hierarchical Ascendant Classification (HAC) of chickpea genotypes 


\section{Conclusion}

During this study, an agro-morphological characterization of some chickpea genotypes was carried out in order to reveal the genetic diversity, 10 chickpea accessions were investigated containing three local varieties, and six breeding line. Fourteen agro-morphological markers were used and chosen according to the recommendations of UPOV (2005), the results obtained show a weak diversity with regard to certain parameters previously considered as a performance component (PH, NP.PT, NS.PT, NP1) according to other studies and their results (Bouri et al., 2019). The analysis of Shannon index average $H^{\prime}$ showed a weak level of diversity for accessions $\left(H^{\prime}=0.29\right)$ and for some morphological trait as weight of leaf $(\mathrm{LW})$ the average value was moderate $\left(\mathrm{H}^{\prime}=0.451\right)$. PCA revealed principal discriminatory characteristics such as plant height, number of pods per plant, number of seeds per plant, number of single seedpods per plant, number of pods per branch. An important agronomic traits gathered in different PCAs tend to stick together, which can be taken into consideration in the breeding program to cause rapid improvement in yield. Cluster analysis also demonstrates the close resemblance between genotypes from different regions, implying that there were no relationships between the geographic origins and genetic diversity of the accessions studied. In summary, a systematic and detailed collection of chickpea genotypes (local breeds and breeding lines) in the country covering all regions followed by a larger study with the inclusion of more sensitive and accentuated molecular techniques will complete the map of the genetic variability of chickpeas that exist in Algeria.

\section{References}

Abdelguerfi A. Laouar M. Hamdi N. Bouzid H. Zidouni F. Laib M. Bouzid L et Zine F 2001. Les légumineuses alimentaires en Algérie : situation, état des ressources phytogenetiques et cas du pois chiche à Bejaia. 3emes journées scientifiques de l'INRAA Bejaia, 11-13avril 2001.

Bayahi K. and Rezgui S. 2015. Agro-morphological characterization and genetic study of new improved lines and cultivars of chickpea (cicerarietinum l.), J. Plant Breed. Genet. 03 (03) 2015. 59-65.

Bouri A. and Gaouar S B S. 2018. Caractérisation génétique des accessions de pois chiche (Tlemcen). Editions universitaires européennes ISBN : 978-620-2-28081-5. 15/02/2018.

Bouri A. Mahdad M Y. Sidhoum M. Gaouar S B S 2019. Effect of the Genotype $\times$ Environment Interaction on the main Components of Yield in Chickpea (Cicerarietinum .L) in Tlemcen, Algeria. Original Research Paper, Genetic and Biodiversity Journal. Gen. Biodv.J, 3(1): 63-69.

Bouri A. Mediouni M R. Ameur AA.Udupa S. Gaouar S B S 2020. Genetic Diversity Analysis in Chickpea (CicerarietinumL) Genotypes Grown in Northwestern Algeria using Microsatellite Markers (SSR). Indian Journal of Agricultural Research, 10.18805/IJARe. A-487.

Hari D. Upadhyaya. Rodomiro O. Paula J. Bramel \& Sube Singh 2001. Phenotypic diversity for morphological and agronomic characteristics in chickpea, core collection, Euphytica 123: 333-342, 2002,Kluwer Academic Publishers. Printed in the Netherland.

IPGRI, 1985. Descriptors for wheat. International Board for Plant Genetic Resources, Rome, Italy.

Jain S K.Qualset C O. Bhatt GM. Wu KK 1975. Geographical patterns of phenotypic diversity in a world collection of durum wheat. Crop Sci 15: 700-704.

Jain S K. Sharma L D. Gupta K C. Kumar V. 2021. Principal Component and Genetic Diversity Analysis for Seed Yield and Its Related Components in the Genotypes of Chickpea (Cicerarietinum L.), January 2021, Legume Research DOI: 10.18805/LR-4489.

KhamassiK .ChaabaneB .KhoufiS . Kharrat M. Ben Naceur M. 2014. Evaluation Agromorphologique de Quelques Génotypes Locaux de Pois Chiche d'Hiver (Cicer arietinum L.) en Tunisie, Journal of New Sciences Volume 5(2). Published May, 01, 2014.

Kumar Ar. Kumar An. Kumar RR. Kumar S. Satyendra.Kumari R and Singh PK 2019. Principal component analysis of Agro-morphogenetic traits in Desichickpea (CicerarietinumL.), (Special Issue 6) $3^{\text {rd }}$ National Conference on Promoting \& Reinvigorating Agri-Horti, 
Bouri et al. 2021. Gen. Biodiv. J, Special issue (Characterization and valorisation of Plants),49-58

Technological Innovations [PRAGATI-2019] (14-15 December 2019.International Journal of ChemicalStudies 2019; SP6: 362-365.

MADR. 2018. Annuaire statistiques du Ministère de l'Agriculture et Développement Rural.

Saxena M C and Singh K.B. 1987. Chickpea breeding. Eds. The chickpea.Wallingford, UK: CAB International, p 207.

Shannon CE and Weaver W 1948. The Mathematical Theory of Communication. University of Illinois Press, Urbana.

UPOV. 2005. Union Internationale pour la Protection des Obtentions Végétales. Principes directeurs pour la conduite de l'examen de la distinction, de l'homogénéité et de la stabilité. Genève, Switzerland.

Varshney R K. Song C. Saxena R K. Azam S. Yu S. Sharpe A G 2013. Draft genome sequence of chickpea (Cicerarietinum) provides a resource for trait improvement. Nat. Biotechnol. 31, 240246. 10.1038/nbt.2491.

Vural and Karasu 2007. Agronomical characterization of several chickpea ecotypes (cicerarietinum

L.) grown in Turkey, August 2007Notulae BotanicaeHortiAgrobotanici Cluj-Napoca 35(2) DOI:

$10.15835 /$ nbha352210. 